\title{
Cladding techniques that achieve a solid metallurgical bond with the least amount of base material dilution - An overview
}

\author{
Ayush Trivedi ${ }^{1,2,3^{*}}$ Vijay Kumar Dwivedi ${ }^{1}$, and Mayank Agarwal ${ }^{4}$ \\ ${ }^{1}$ GLA University, Mathura 281406, India \\ 2 Pranveer Singh Institute of Technology (P.S.I.T.), Kanpur 209305, India \\ ${ }^{3}$ Dr. A.P.J. Abdul Kalam Technical University (A.K.T.U.), Lucknow 226031, India \\ ${ }^{4}$ Institute of Engineering Technology, Dr. Ram Manohar Lohia Avadh University (Dr.R.M.L.A.U.), Ayodhya, India
}

\begin{abstract}
Metals and alloys can undergo intergranular corrosion attack, wear and ultimately can result in failure under various service conditions. To reduce this possibility of failure by different modes, metals and alloys are employed with certain surface treatment processes. Out of numerous surface treatment processes available today cladding has evolved itself as one of the noble techniques in this era to provide and act as a protective layer that enables the component or specimen to withstand and enhance the service life under extreme conditions. There is a various additive method of cladding who found to be economical and efficient over the perspective of providing a good metallurgical bond with the least possible dilution of the base material. This study tries to figure out the possibilities concerning conventional and unconventional cladding techniques based on processing techniques, metallurgical bonding, advantages associated, and limitations as attached to it.
\end{abstract}

\section{Introduction}

The current study tries to focus on a unique study in surface treatment methods in the context of various cladding techniques with strong metallurgical bonding and minimal substrate dilution. In general, a coating is a widely used surface treatment method that involves applying a layer of appropriate materials to substrates with desired qualities. Metallic coatings on metals, alloys, and nonmetals offer several benefits. Metals' superior characteristics can be better utilized by applying appropriate coatings to the functional surface of a metal, alloy, or non-metallic substrate. [1-2]

For example, stainless steel (SS) bears good mechanical properties but it has no electrical and thermal conductivity so a coating can be a pragmatic solution to such problems as it can compensate for these deficiencies. [2]

Cladding is a typical surface modification/treatment technique that involves partial melting of the substrate and complete melting of externally supplied powders onto the substrate to develop and encapsulate the dominating and prevailing characteristics of appropriate materials on surfaces of desired thickness. The cladding process is characterized by excellent metallurgical bonding with the little dilution of the base material. A small fragmented zone of the substrate material melts during the cladding process, forming a strong metallurgical connection with the molten wear-resistant material, which is usually encapsulated as powder. [3]

The demand for an effective surface coating process has grown considerably as a result of the industrial revolution. Laser-based cladding, TIG cladding, microwave cladding, PVD, hybrid cladding, CVD, and other techniques are only a few examples. Erosion can be caused by high velocity and temperature, and this phenomenon of simultaneous action for metal removal is known as ablation [4]. As a result, the metal used must be ablation-resistant.[4]

\section{Cladding}

It is a useful way of surface treatment for protecting the target material from adverse conditions, concerning environmental, service, or wear and, in some situations, for improving the material's performance to meet mechanical and metallurgical criteria.[1]

\subsection{Cladding Procedure}


Cladding seems to be the process of joining two discrete sets of materials together using surface engineering techniques for the improvement in their performance more than as compared to their original state [2]. It involves multiple processes such as physical fusion and chemical deposition. The metallurgical bonds are formed between the materials, combining them into a single unit. Cladding is often defined by partial dilution of the base material, with metallurgical bonding forming within the substrate and deposit as a result. The process to clad a material/specimen is bifurcated into discrete segments mainly conventional cladding and unconventional cladding processes.

\section{Unconventional Cladding processes}

\subsection{Microwave cladding}

\subsubsection{Microwave}

Microwaves are a part of the electromagnetic spectrum with wavelength ranging from "1 $\mathrm{mm}$ to $1 \mathrm{~m}$ " [5] and frequencies ranging from "300 $\mathrm{MHz}$ to $300 \mathrm{GHz}$ " [5]. Radar, mobile devices, ovens, Wi-Fi, and navigation systems all use frequencies in this region of the electromagnetic spectrum. "Two frequencies, controlled by the Federal Communications Commission (FCC) and utilized for scientific, industrial, and medical reasons, are typically used for microwave processed heating are $2.45 \mathrm{GHz}$ and 0.915 $\mathrm{GHz}$ frequencies. Microwave furnaces have recently been created for material processing at variable frequencies ranging from 0.9 - $18 \mathrm{GHz}$.[5]

Microwave heating was created around 70 years ago, although it is still regarded as a relative newcomer in the field of material sintering and processing. [3,6]

\subsubsection{Phenomenological perspectives}

Microwaves belong to the electromagnetic spectrum's radio waves and infrared frequencies. Microwaves can pass through materials and can be absorbed, scattered, or transmitted. Interaction of the microwaves with the material is required for absorption and reflection, whereas transmission is the consequence of incomplete reflection and partial absorption. [6,8] The substance generates energy in the form of heat largely through absorption during the contact. Microwaves may interact with solid, liquid, and gases, and they can be heated within specific conditions. Gases can also be stimulated by microwaves to produce plasma, which is helpful for processing.[8] Other materials, depending on their chemical components, shape, temperature, and microwave frequency, reflect and absorb heat to varying degrees. Metals, particularly in bulk form, are excellent reflectors of microwave radiation and do not become overheated by them.[8]

\subsubsection{Procedural processing technique - (Microwave coating/cladding)}

The steps in the microwave cladding process are as follows: [9]

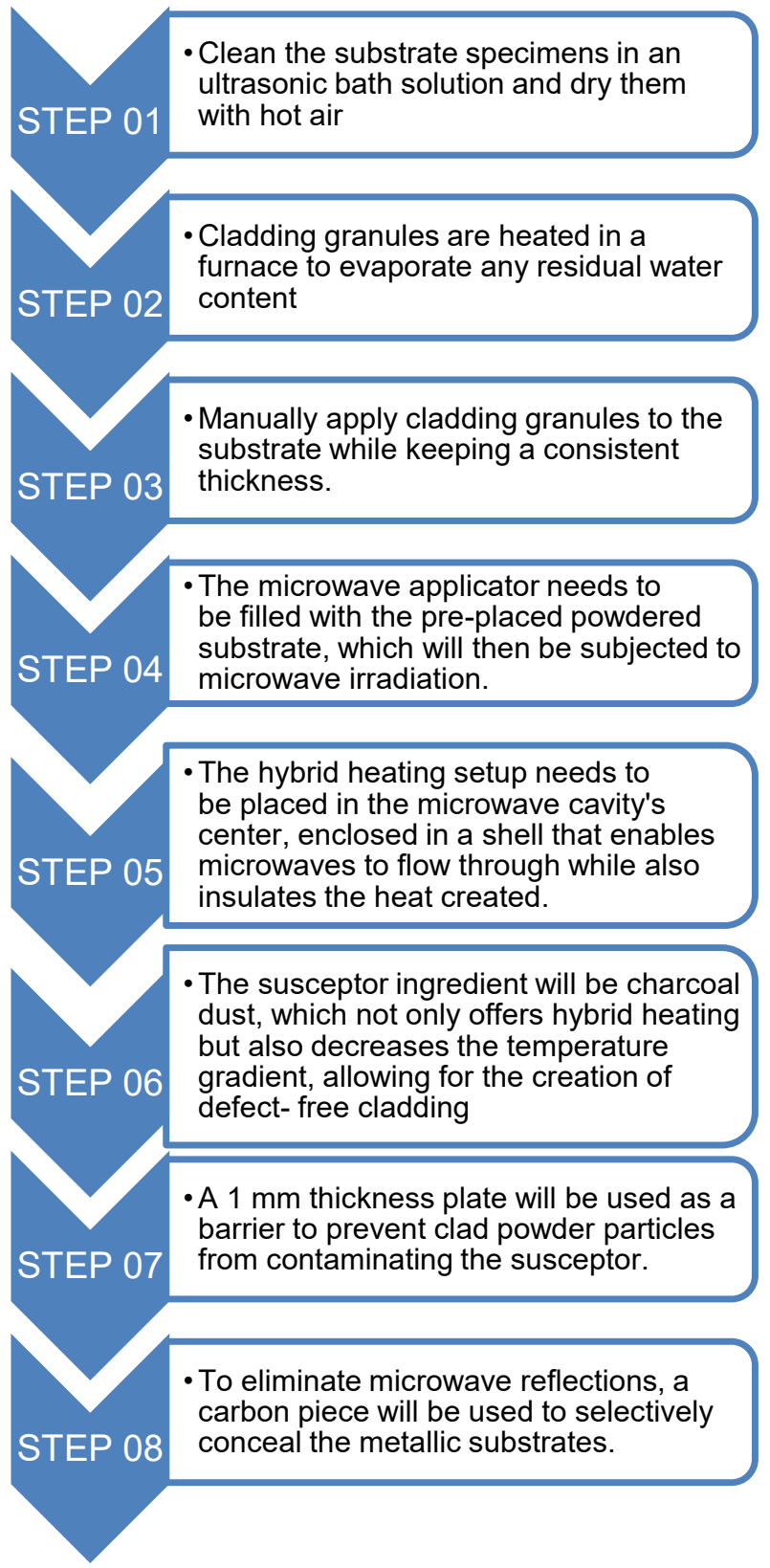

Figure-01: Steps of Microwave Cladding 


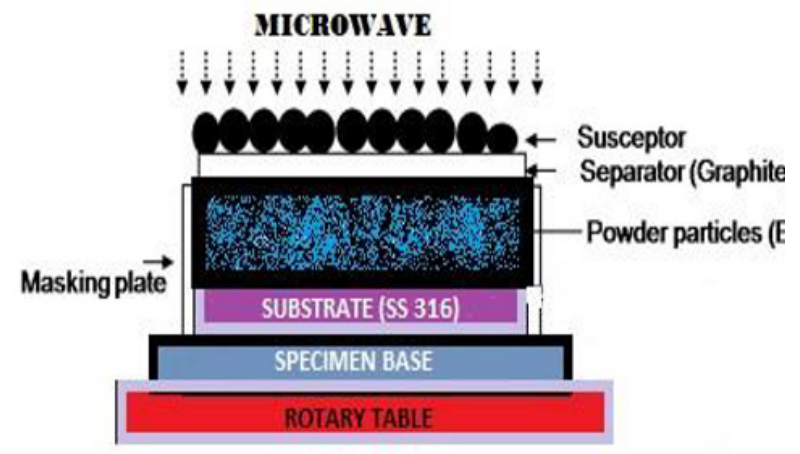

Microwave cavity

Figure-02: Microwave processing layout [10]

\subsubsection{Microwave processing's potential}

Microwave processing has received a lot of attention because of its many advantages. Some of the benefits are as follows: [11]

- The primary advantage of employing microwaves is that they save time and energy, allowing you to produce more products. Microwave heating proceeds at the atomic level, resulting in homogenous heating of the substance. [11].

- The mechanical characteristics are improved by the fine microstructures created in this technique. With varying degrees of dilution, microwave cladding displays strong metallurgical bonding with the substrate. [3940]

- Being an electromagnetic nature, microwave causes dipolar rotation and ionic conduction which acts as a fundamental technique that transfers instantaneous energy in the form of heat from microwave to a substance.

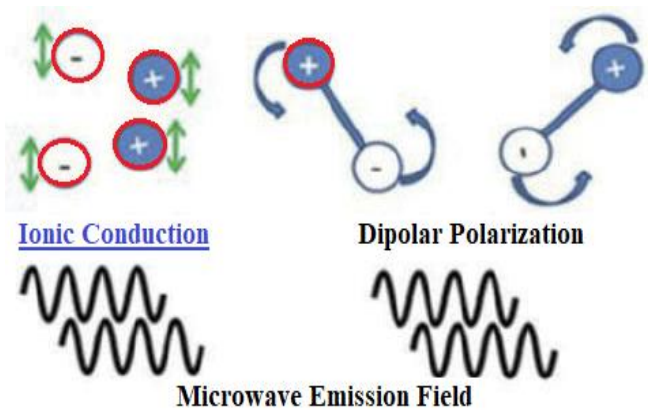

Figure-03: Dipolar \& Ionic conduction [6]

- Microwave heating does not affect the structure of a molecule.[10]
- Classified as a green manufacturing process in material processing and also known to be inside to outside heating process.[12]

- MWH has a consistent microstructure and retains its shape [13]. Sintered density is higher, flexural strength is stronger, and pores are distributed uniformly.[14]

- When compared to traditional approaches, this method has a lower environmental impact. Microwave heating can also be used to combine two non-similar metals.[39]

\subsubsection{Role of temperature, binders, and incident frequency in microwave processing.}

At room temperature, metals do not absorb appreciably at $2.45 \mathrm{GHz}$. Because the microwave absorption coefficient for metals at $2.45 \mathrm{GHz}$ radiation is much lower at room temperature due to the skin effect, adaptation of microwave energy in processing metallic materials is difficult. This makes it extremely difficult to heat metallic objects without utilizing a hybrid heating technology that combines conduction and microwave radiation.[15]

Additionally, in bulk metals, "sinusoidal microwaves can penetrate effectively up to the skin depth $(\delta)$. The skin depth of any material is a function of wave angular frequency $(\omega)$ of the microwave radiation, conductivity $(\sigma)$, and magnetic permeability $(\mu)$ of the material body". It's calculated using an equation - 1 [16].

$\delta=\sqrt{(2 /(\omega . \mu . \delta))}$

equation...1

The skin depth of electrically conductive materials is much lower; for reference, the skin depth of bulk copper at ambient temperature is $1.3 \mathrm{~mm}$ [17]. As a result, metals were previously thought to be unsuitable for processing in microwaves at room temperature. This condition, on the other hand, does not prevail in metallic powder compacts. Microwaves can reach deep into metal powders compact as the skin depth grows [17]. As a result, their absorption may be enhanced by raising the temperature or adding absorbent components like silicon carbide or binders, as well as modifying their microstructure and defect pattern by modifying their shape from bulk to granules and adjusting the frequency of incoming radiation. Microwaves may be carried, stored, and used at room temperatures as well as at greater temperatures because of the broad spectrum of interactions that occur among microwaves and different materials. [35-36]

\subsection{Laser Cladding}

One of the most commonly used surface engineering techniques is laser cladding. It is the melting of the coating material and a fine surface layer of the substrate 
using a scanning laser beam to produce a surface layer. The basic goal of laser cladding is to create a thin interfacial coating of metal or alloys on a particular substrate with the least amount of dilution possible to improve surface wear and corrosion resistance. [18].

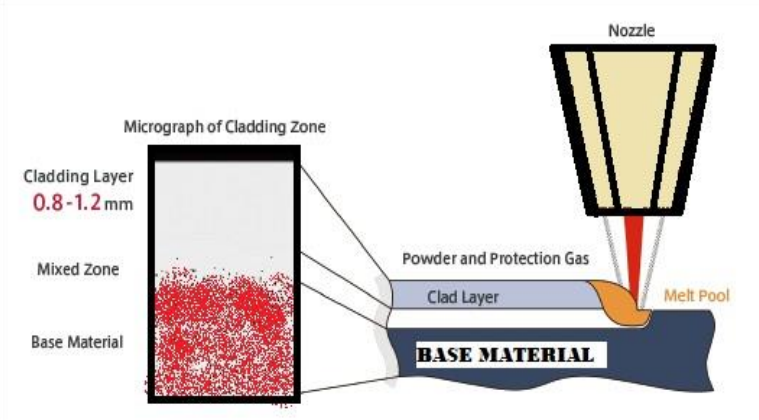

Figure-04: Laser cladding process [19]

Surface engineering technologies and procedures enable the creation of a variety of composite and complicated coatings. Thermionic assisted spraying, plasma and laser melting of galvanic coating, diffusion layer, or precoat in the form of pastes are the most commonly documented in the literature. It is possible to change the surface characteristics of many materials such as light metals, various classification of steel, and cast-iron using laser technology. The laser cladding method, in which a specially constructed nozzle simultaneously produces a laser beam and adds powdered granules mixes to it, is critical for a variety of industrial disciplines. As a result, it is simple to create a coating with new, distinct characteristics. 5-axis CNC laser processing centers are utilized in industry to allow manufacturing of coatings only in zones where they are necessary. Wear resistance is a major issue that is frequently explored in research. The use of laser cladding technology to manufacture wear-resistant coatings on agricultural implements might be a suitable example. Because such instruments only wear away in some zones during utilization, changing their whole surface is economically unnecessary. Increasing durability solely in the areas that are subjected to wear appears to be a viable option. Diffusion and other techniques that are more energy and time-consuming may be viable alternatives that can be successfully replaced through the laser cladding technique. $[20,41,45]$

\subsubsection{Laser Cladding Processing Technique}

The traditional laser cladding process is explained in Figure 4. Because of the cost savings and exact coating flexibility provided by the high-intensity focused beam [21], this is the preferred method. It has been debated for decades for the numerous benefits that may be obtained by combining everyday emerging technology. With the aid of a modern computer and CNC equipment, the procedure is entirely automated. [22]. Due to increased industry demand, it is important to automate the process to minimize processing time and lead time in manual techniques. Not only one or two materials bonded together in the cladding process, but many additional elements can be combined in the blender and alloyed together as per the needs. [23,24].

\subsubsection{Processing parameter (Laser Clad)}

There are numerous process parameters for laser cladding. The following are the most important parameters:

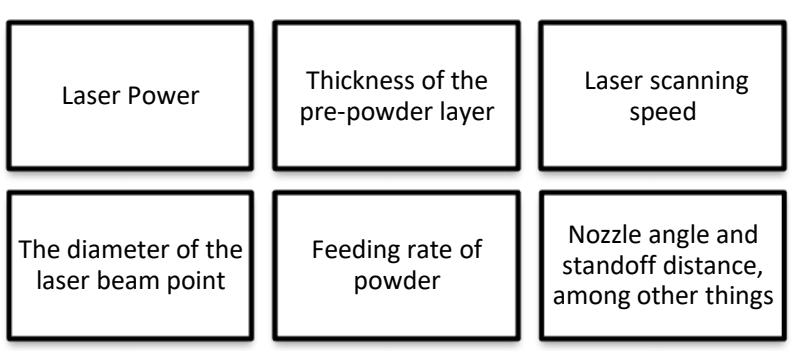

Figure-05: Laser cladding (Processing Parameters)

The cladding process divided the LC process parameters into five categories: machining parameters, laser beam characteristics, product characteristics, laser clad characteristics, and cladding powder characteristics. To optimize the process, the process parameters should be properly managed.

\section{Machining Parameters}

\begin{tabular}{|c|c|c|c|c|}
\hline $\begin{array}{c}\text { Scanning } \\
\text { Speed }\end{array}$ & $\begin{array}{c}\text { Direction } \\
\text { of Clad }\end{array}$ & Overlap & $\begin{array}{c}\text { Shielding } \\
\text { gas }\end{array}$ & Preheating \\
\hline
\end{tabular}

\section{Laser Beam Characteristics}

\begin{tabular}{|c|c|c|c|c|}
\hline $\begin{array}{c}\text { Spot } \\
\text { Dimension }\end{array}$ & Wavelength & Polarization & $\begin{array}{l}\text { Laser } \\
\text { Power }\end{array}$ & $\begin{array}{l}\text { Beam } \\
\text { profile }\end{array}$ \\
\hline \multicolumn{5}{|c|}{ Cladding Powder Characteristics } \\
\hline $\begin{array}{l}\text { Injection } \\
\text { angle }\end{array}$ & Feed rate & $\begin{array}{c}\text { Powder } \\
\text { composition }\end{array}$ & $\begin{array}{c}\text { Nozzle } \\
\text { distance }\end{array}$ & $\begin{array}{c}\text { Particle } \\
\text { shape \& size }\end{array}$ \\
\hline
\end{tabular}

\section{Product Characteristics}

\begin{tabular}{|c|c|c|}
\hline Geometry & $\begin{array}{c}\text { Thermal \& Metallurgical } \\
\text { Properties }\end{array}$ & $\begin{array}{c}\text { Material } \\
\text { Composition }\end{array}$ \\
\hline
\end{tabular}

\section{Laser Clad Characteristics}

\begin{tabular}{|l|l|c|c|c|}
\hline Microstructure & Dilution & $\begin{array}{c}\text { Cracking } \\
\text { porosity }\end{array}$ & $\begin{array}{c}\text { Surface } \\
\text { Roughness }\end{array}$ & $\begin{array}{c}\text { Residual } \\
\text { Stresses }\end{array}$ \\
\hline
\end{tabular}


Figure-06: Process of laser cladding context diagram. [25]

\subsubsection{LC microstructural evaluation}

A stereoscopic microscope is used to examine the surface quality following the laser cladding procedure. Track widths, porosity, and the existence of fractures, as well as heat tints of MMC coatings, are all examined. Non-destructive methods like dye penetrant examination can also be used to evaluate coatings. [25] (NDT is a tool for assessing weld uniformity, along with assessing the quality of the coating.)

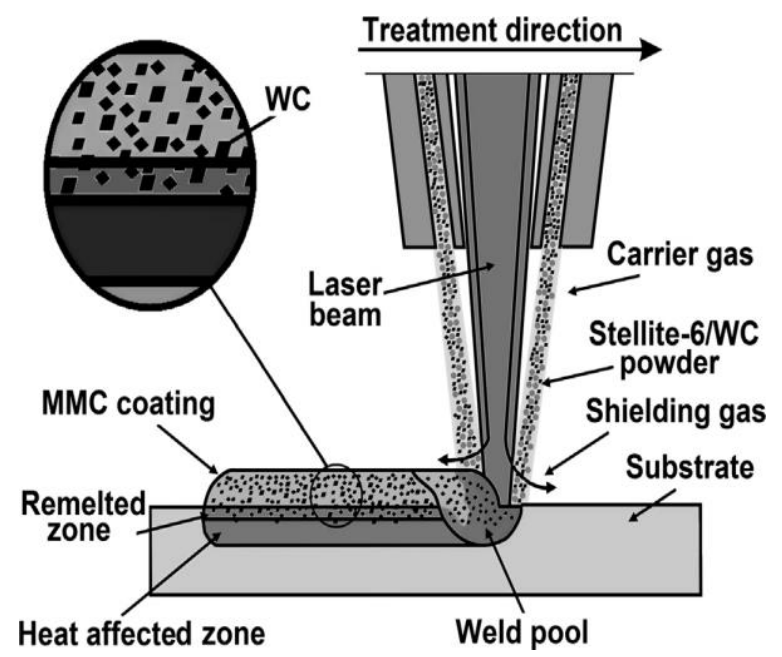

Figure-07: Coherent laser cladding. [19]

\subsubsection{Laser Cladding Deficiency}

Dendritic microsegregation, which appeared with a variety of cooling speeds on the cross-section of coatings, was a common feature of most composite coatings. The following are the major flaws discovered during the laser cladding process. i.e.,

- Results in overall high operating and maintenance cost. (High setup cost) [26]

- Has a low degree of deposition efficiency. [2627]

- Materials processing is prone to solidification cracking due to the increased rate of cooling.[26]

- An intense heat source might result in localized thermal deformation and residual strains. [26]

The addition of WC principal carbides, as well as modification of the steel substrate with the modified surface layer near the melting line, namely the connection area between the coating and the substrate, had a significant impact on the shape differences of dendrites. Coatings made with a greater laser beam power have the most microstructure non-uniformity. It was caused by rapidly chilling the substrate after combining it with an additional substance, removing the chance to homogenize the coating. [1,37-38]

\section{Conventional Cladding Process}

\subsection{TIG cladding process}

The TID cladding technique is a newly developed method of surface covering. It nearly completely removes all of the inconveniently expensive unneeded equipment $[3,28]$. The procedure has been proven to be relatively easy and adaptable, and it may be utilized at any stage of the material's development. The TIG welding technique is quite similar to the TIG cladding equipment. The material to be coated is first painted with clad material and put in a die that is $1 \mathrm{~mm}$ larger than the base material; this phenomenon is then added for uniform-clad material distribution, and then a TIG arc is conducted over the surface for the required coating width. The graphical depiction of the TIG cladding process is shown in Figure 08, which provides a thorough picture of how the TIG cladding method works. [29].

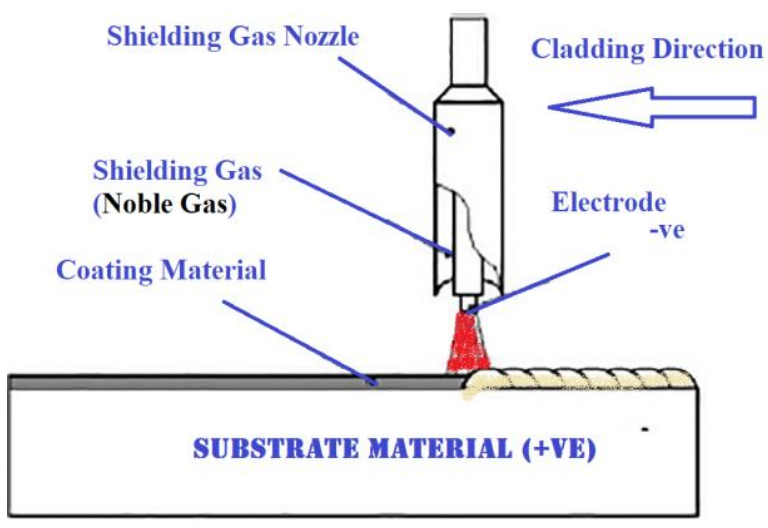

Figure-08: TIG cladding process [29]

\subsection{Conductive heating (Conventional heating)}

In conductive heating modes of heat transfer is due to conduction, convection, radiation, or a combination of them. It is regarded as a slow and inefficient mode of heating as energy transfers from one molecule to another through lattice vibration thereby, generates problems related to thermal gradient due to change in microstructure with varying mechanical properties. It is also known to be outside to inside mode of heating [3033]. In correlation to unconventional sources of cladding conductive mode of cladding lacks in various domains. Unlike traditional furnaces, the material to be treated in a microwave furnace interacts with "cold" microwaves rather than radiant heat since the substance creates the heat, and heating is more volumetric and may be relatively fast and selective. A comparative study (Table:01) reveals the difference pertains to MW 
processing vs conventional processing of lead, tin, aluminum resulting in the MW process over conventional one based on melting time and rate of temperature rise. Furthermore, heating is immediate in terms of power. When appropriately regulated, these attributes result in improved product homogeneity, faster production throughput, less floor space, and less wasteful heating due to the reduced furnace, valves, conveyor belts, etc. [34,42-44]

Table-01: Melting time and heating rate for microwave and conventional melting modes are displayed. Using a microwave instead of a conventional furnace cut the time it took to melt metals in half along with the energy required by a traditional furnace, the microwave required half the energy. [11]

\begin{tabular}{|c|c|c|c|c|}
\hline \multirow{2}{*}{ 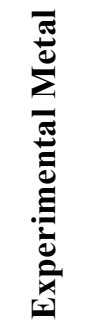 } & \multicolumn{2}{|c|}{ MW (1300 W) } & \multicolumn{2}{|c|}{ Muffle $(2500 \mathrm{~W})$} \\
\hline & 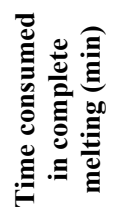 & 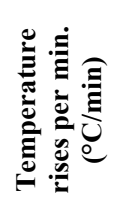 & 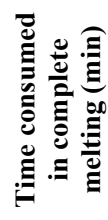 & 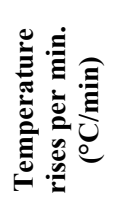 \\
\hline $\begin{array}{l}\text { Tin } \\
\text { (Sn) }\end{array}$ & 5.0 & 40.0 & 11.0 & 24.0 \\
\hline $\begin{array}{c}\text { Lead } \\
(\mathrm{Pb})\end{array}$ & 6.0 & 51.0 & 14.0 & 21.0 \\
\hline$(\mathrm{Al})$ & 9.0 & 82.0 & 29.0 & 24.0 \\
\hline
\end{tabular}

\section{Conclusion}

Despite the other conductive processes, the unconventional cladding technique was shown to be one of the best methods of surface coating in this finding. Many developments have been made in this field over the years, and technological advancements have increased the opportunity to work for the betterment of material quality and performance during a lifetime. There are many different types of cladding processes, each with its own set of benefits and drawbacks. When considering cost along with excellent metallurgical bonding considerations in terms of laser cladding or microwave cladding can be chosen since they provide good bonding with the substrate, but they somehow lack as they are not suitable for poor conditions or intricate operations, where, TIG cladding can be preferable. As a result, the best technology must be chosen based on the specific requirements, taking into account all parameters pertain to physical and chemical characteristics.

The authors declare that there is no financial and personal interest in this.

\section{References:}

1. V.K. Rai, R. Srivastava, S.K. Nath, S. Ray, Wear, 231, 265 (1999)

2. S. Buytoz, M. Ulutan, M. M. Yildirim, Appl. Surf. Sci., 252, 1313 (2005)

3. D. Gupta, A. K. Sharma, Journal of Manufacturing Processes, 16, 176, (2014)

4. C.T. Kwok, H.C. Man, F.T. Cheng, Surf. Coat. Technol., 99, 295 (1998)

5. R. J. Lauf, D. W. Bible, A.C. Johnson, C.A Everleigh, Microwave Journal, 36, 24 (1993)

6. V. G. Gude, P. Patil, E. M. Guerra1, S. Deng, N. Nirmalakhandan, Sustainable chemical process, 33, (2013)

7. D.E. Clark, J.R. Laia, Materials Processing, 26, 299, (1996)

8. R. Yokeswaran, V. Vijayan, T. Karthikeyan, B. S. Kumar, G. S. Kumar, Materials Today: Proceedings, 21, 773, (2020)

9. A. Pathania, S. Singh, D. Gupta, V. Jain, J. Manuf. Processes, 20, 79, (2015).

10. S. C. Srivastava, Q. Murtaza, P. Kumar, Materials Today: Proceedings, 21, 1533, (2020)

11. S. R. More, D. V. Bhatt, J.V. Menghani, Materials Today: Proceedings, 4, 9902 (2017)

12. A. K. Sharma, S. Aravindan, R. Krishnamurthy, Mater Lett., 50, (2001)

13. C. Leonelli, P. Veronesi, L. Denti, A. Gatto, L. Iuliano, Journal of Materials Processing Technology,205, 489 (2008)

14. Anklekar, Rupendra, Agrawal, Dinesh, Roy, Ritanjal, Powder Metallurgy, 44, 355 (2001)

15. D. E. Clark, Microwave Processing, 22, 48 (2000)

16. C. Liu, N. Chiung, B. Ki, A. Walters, B. Vannice, C. Albert, Lett., 26, 9 (1994)

17. D. Gupta, A. K. Sharma, J. Process Mechanical Engineering, 226, 132 (2011)

18. S. Ocylok, A. Weisheit, I. Kelbassa, Physics Procedia, 5, 359 (2010)

19. D. Bartkowski, A. Mtynarczak, A. Piasecki, B. Dudziak, M. Gościański, A. Bartkowska, Optics \& Laser Technology, 68, 191 (2015)

20. C. P. Paul, S. K. Mishra, P. Tiwari, L. M. Kukreja, Optics \& Laser Technology, 50, 155 (2013)

21. W.J. Buehler, F.E. Wang, Ocean Eng., 1, 105 (1968)

22. R.H. Richman, A.S. Rao, D.E. Hodgson, Wear, 157, 401 (1992)

23. S.K. Wu, H.C. Lin, C.H. Yeh, Wear, 244, ,85 (2000)

24. H. Matsunami, T. Kimoto, Mater. Sci. Eng., R: Rep. 20, 125 (1997)

25. S. R. Bhatt, D.V. Menghani, Materials Today: Proceedings,4, 9902 (2017) 
26. C. P. Paul, B. K. Gandhi, P. Bhargava, D. K. Dwivedi, L. M. Kukreja, Journal of Materials Engineering and Performance, 2, 4463 (2014)

27. K. Jayakumar, T. S. Kumar, B. Shanmugrajan, International journal of advance multidisciplinary research, 2, 72 (2015)

28. C.T. Kwok, F.T. Cheng, H.C. Man, Mater. Sci. Eng., 29, (2000)

29. Gouthama T. R., IOP Conf. Ser.: Mater. Sci. Eng., 44-54, (2016)

30. K. Sharma, S. Aravindan, R. Krishnamurthy, Mater Lett.,50, 295 (2001)

31. S.M. Lingappa, M.S. Srinath, J. Amarendra, Braz. Soc. Mech. Sci. Eng., 40, 1 (2018).

32. S. Singh, D. K. Goyal, P. Kumar, A. Bansal, Material research express, 6, 1528 (2020)

33. Gouthama T. R., IOP Conf. Ser.: Mater. Sci. Eng., 44, (2016)

34. E.T. Thostenson, T. W. Chou, Composites: Applied science and Manufacturing, 30, 1055 (1999)

35. M. Eroglu, N. Ozdemir, Surf. Coat. Technology, 154, 209 (2002)

36. A. K. Sharma, R. Krishnamurthy, J Eur Ceram Soc., 22, 2849 (2002)

37. S.W. Wang, Y.C. Lin, Y.Y. Tsai, J. Mater. Proc. Technol., 140, 682 (2003)

38. A. Bloyce, Proc. I. Mech E J - J Eng. Tribol.,212, 467 (1998)

39. S. Zafar, A. K. Sharma, Tribol. Int., 91, 14 (2015)

40. A.K. Sharma, D. Gupta, Indian Patent, 527, 2010.

41. A. K. Sharma, R. Krishnamurthy, J Eur. Ceram. Soc., 22, 2849 (2002)

42. S. Ocylok, A. Weisheit, I. Kelbassa, Physics Procedia, 5, 359 (2010)

43. P. K. Farayibi, Ph.D. Thesis, University of Nottingham, 7, (2014)

44. M. Masanta, S. M. Shariff, A. R. Choudhury, Wear, 271, 1124 (2011)

45. C. P. Paul, S. K. Mishra, P. Tiwari, L. M. Kukreja, Optics \& Laser Technology, 50, 155 (2013) 